\title{
Erratum to: The Politics of Health Policy Reform in the UK: England's Permanent Revolution
}

Calum Paton

Erratum to: Acknowledgments

DOI 10.1057/978-1-137-47343-1

The original version of this article was inadvertently published without the Acknowledgments section, which has been included now.

The online version of the original book can be found under DOI 10.1057/978-1-137-47343-1

(C) The Author(s) 2016 